\title{
Pharmacological Ascorbate
}

\author{
National Cancer Institute
}

\section{Source}

National Cancer Institute. Pharmacological Ascorbate. NCI Thesaurus. Code C156461.

\begin{abstract}
A high dose (HD) of ascorbic acid, a pro-oxidant agent, with potential antineoplastic and radio-chemo-sensitizing activities. Upon intravenous (IV) administration, pharmacological ascorbate is able to generate reactive oxygen species (ROS) by donating an electron to oxygen ( $\mathrm{O} 2)$ and forming hydrogen peroxide ( $\mathrm{H} 2 \mathrm{O} 2)$, thereby causing oxidative stress and overwhelming the cell's anti-oxidant defense mechanisms. This induces DNA doublestranded breaks (DSBs) and cell death. T umor cells are highly susceptible to ascorbatemediated oxidative stress and cytotoxicity while normal, healthy cells are mostly unaffected. This induces the cell death of susceptible tumor cells and decreases tumor cell growth. Higher plasma ascorbate concentrations are achieved upon higher intravenous doses of ascorbate; oral administration of ascorbate is limited and uptake does not increase after a certain amount is administered. Only IV ascorbate produces plasma concentrations high enough to induce ascorbate-mediated cytotoxicity to susceptible tumor cells. In addition, HD parenteral ascorbate enhances radio- and chemo-sensitivity of susceptible cancer cells.
\end{abstract}

